\title{
Decoración parietal de un edificio paleocristiano en el Conjunto Arqueológico de Cástulo
}

\section{Teresa López-Martíneza ${ }^{a}$, Víctor J. Medina-Flórez ${ }^{a}$ y Ana García Bueno ${ }^{a}$}

${ }^{a}$ Departamento de Pintura, Universidad de Granada. Avenida de Andalucía, S/N, C.P.: 18071, Granada. tlopez@ugr.es, vmedina@ugr.es, $\underline{\text { anagar@ugr.es }}$

\begin{abstract}
Resumen
El pasado octubre de 2014 se conoció el hallazgo, en el Conjunto Arqueológico de Cástulo, de una patena de vidrio decorada con la Traditio Legis. Coetáneamente, y en el mismo edificio, se hallaron unos revestimientos murales datados a mediados del siglo IV, objeto de estudio del trabajo que aquí se presenta.

Se han conservado dos paños de pintura mural de considerables dimensiones que decorarian la pared de un banco corrido; el objetivo de este trabajo ha sido el estudio de su decoración así como la caracterización de sus materiales constitutivos y de su técnica de ejecución. Estas pinturas presentan un esquema de decoración contínua, más común en decoraciones de techos que de paredes, basada en elementos geométricos, como bandas diagonales de colores diversos, y motivos vegetales, concretamente flores inscritas en rombos dobles y en cuadrados simples. Las pinturas han sido ejecutadas al fresco sobre un solo estrato de mortero de cal y árido, para lo que se han empleado pigmentos típicos de la paleta romana como el hematites o las tierras verdes.
\end{abstract}

Palabras clave: pintura mural, tardoantigüedad, Castulo, pigmentos, mortero, decoración.

\begin{abstract}
Last october 2014, a glass paten decorated with the Traditio Legis was discovered in the Archaeological Site of Castulo. At the same time, and in the same building, some wall coverings dated to the middle of the fourth century were discovered too; they are the object of study of the present work.

Two fragments of mural painting of considerable dimensions have been preserved. These fragments would decorate the wall of a bench; the objective of this work has been the study of its decoration as well as the characterization of its constituent materials and its execution technique. The wall coverings present a continuos decoraction scheme, more common in ceiling decorations than walls, bases on geometric elements, like diagonal lines of various colors, and vegetable motifs, specifically flowers inscribed in double diamonds and single squares. The paintings have been executed in fresco on a single layer of lime mortar. Pigments typical of the roman palette have been used like hematite or green earth.
\end{abstract}

Keywords: wall painting, late antiquity, Castulo, pigments, mortar, decoration. 


\section{Introducción}

"Ciudad grande e inmune", así es como describía Tito Livio, famoso historiador romano, a Castulo, una de las ciudades de Hispania más mencionada en los textos clásicos (Contreras, 1967). Emplazada entre los municipios de Linares, Lupión y Torreblascopedro, en la provincia de Jaén, fue declarada Conjunto Arqueológico en el año 2011; desde ese momento, y de la mano del equipo de FORVM MMX se reanudaron, de manera más continuada, las excavaciones en el mismo, dando lugar a importantes hallazgos (Calabria y Zalbidea, 2019).

Entre las últimas edificaciones documentadas destaca una construcción destinada al culto paleocristiano y fechada a mediados del siglo IV d.C., denominada Edificio E, en la que se ha hallado un plato de vidrio decorado con la escena de la Traditio Legis (Blázquez, 2015) y unos revestimientos murales, objeto de estudio del trabajo que aquí se presenta.

\section{Contexto arqueológico}

Diversas prospecciones realizadas por Marcelo Castro señalan los orígenes del asentamiento de Castulo a finales del tercer milenio, mientras que su surgimiento como centro principal de la región se debe emplazar junto con la consolidación de las actividades metalúrgicas en Sierra Morena, en el Bronce Medio (Castro, 1994).

Varios son los factores que propiciaron el desarrollo de la ciudad. En primer lugar, la conveniente situación que tenía para controlar el tránsito de mercancías por los itinerarios ya que su emplazamiento entre la Meseta, la Alta Andalucía y el Levante español resultaba el punto de cruce de distintos caminos (García-Gelabert, 1987); asimismo, la conexión con el río Guadalquivir permitía la comunicación que la orografía del terreno hacía imposible. En segundo lugar, su producción minera; la región en la que se sitúa Castulo es muy prolífica en minerales, siendo ésta una ciudad productora de hierro, cobre, plomo, anglesita y plata. En tercer lugar, el clima mediterráneo del que disfruta y que favorece el cultivo del olivo, del cereal, del algodón y de diversos productos de huerta (Blázquez y García-Gelabert, 1988). Gracias a ello, los asentamientos se sucedieron desde el Bronce Final, dando lugar a dos sectores diferenciados: el oppidum oretano, donde se asienta la ciudad romana, que alcanzó su esplendor durante la República y el Alto Imperio, y otro constituido por necrópolis, pequeños poblados, talleres y el puerto fluvial, localizado extramuros. Dentro del oppidum, y gracias a las excavaciones realizadas por el proyecto FORVM MMX durante los años 2011 y 2014 se acotaron dos áreas de excavación denominadas como "área 1" y "área 2"; en la primera de ellas, coincidente con la denominada por el profesor Blázquez como "Conjunto arquitectónico del Olivar", se identificaron unas termas de época Flavia y un edificio público alto imperial (Blázquez y García-Gelabert, 1994), mientras que en la segunda, localizada al suroeste de la primera, se documentó un edificio público de época altoimperial, al que se ha denominado Edificio D, y otra estructura, más tardía, situada al norte de la anterior, denominada Edificido E (Calabria, 2013; Ceprián et al., 2014) (Fig. 1).

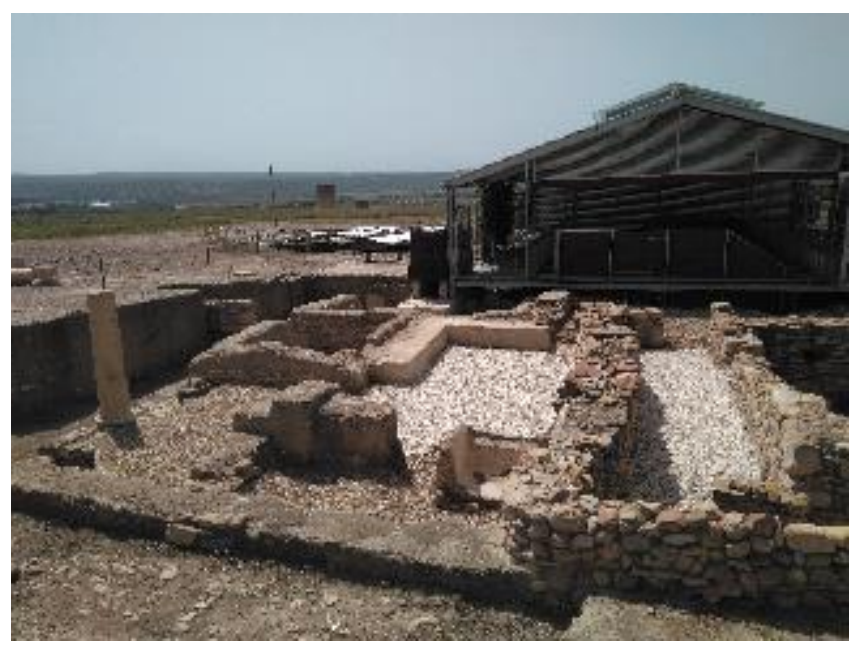

Fig. 1 En primer plano, Edificio E con el banco corrido junto al cual se descubrieron los revestimientos murales. En segundo plano, Edificio D, cubierta de la Sala del Mosaico de los Amores 
A pesar de que el Edificio E se encuentra todavía en fase de estudio, se sabe con seguridad que su función estaría relacionada con el culto cristiano, aunque no necesariamente con la eucaristía; en él se pueden distinguir dos zonas. En la zona oriental se ha hallado un espacio abierto, pavimentado con opus caementiciu, en el que se localiza una pila rectangular así como un banco corrido; a los pies de dicho banco se descubrieron los revestimientos murales de época tardoantigua que aquí se presentan. Por el contrario, en la zona occidental se dispone una sucesión de habitaciones cuyas funciones abarcan desde la agricultura hasta el tratamiento de metales, quedando especificadas por los restos materiales en ellas encontrados, y un espacio meridional donde se encuentra un depósito de agua de más de cinco metros de profundidad, excavado parcialmente (Expósito et al., 2015).

En cuanto a la cronología del edificio, su inicio se puede datar en la segunda mitad del siglo IV d.C., si bien no es posible descartar aún una cronología más temprana; por el contrario, para su momento final se debe hacer una distinción entre la zona oeste y la zona oriental. De este modo, la cronología más tardía que se puede fechar en la zona este es la de mediados del siglo V d.C.; ésta viene dada por las cerámicas finas de mesa halladas en los últimos estratos de uso y abandono, caracterizadas por ser un conjunto abundante de terra sigillata hispánica tardía meridional, entre las que aparecen la forma T.S.H.T.M. 10, y algunos fragmentos de terra sigillata claras D, como una forma Hayes 61, que determinan una horquilla cronológica entre finales del siglo IV y principios del siglo $\mathrm{V}$ d.C.. Posteriormente, este espacio volvió a ser empleado ya que en él se excavará, entre finales del siglo VI d.C. y principios del siblo VII d.C., una tumba doble en la que se localiza un broche de cinturón de placa rígida, que permite la datación de la misma, perteneciente a uno de los individuos enterrados. A su vez, tanto la cerámica como las monedas encontradas en la zona oeste, indican una pervivencia mayor de la misma como construcción cristiana (Ceprián et al., 2014). Finalmente, entre los siglos VII y VIII d.C. dicha zona parece acondicionarse como lugar de producción.

\section{Metodología}

En un trabajo de este tipo es necesario emplear una metodología diferenciada y específica, orientada a la consecución de los objetivos propuestos. Su aplicación rigurosa es imprescindible para que finalmente se puedan establecer conclusiones seguras y fiables.

\subsection{Documentación gráfica y fotográfica}

En primer lugar, se ha realizado una exhaustiva documentación gráfica y fotográfica de los revestimientos que aquí se presentan. Para ello, se ha utilizado la metodología comúnmente aceptada consistente en la realización de fotografías y de calcos o dibujos de la decoración (Barbet, 1987).

En el caso de las fotografías realizadas, éstas han sido tomadas con escala y carta de color, con una cámara fotográfica Nikon D5300 con pantalla abatible y un objetivo AF-S Nikkor 18-105 mm con VR empleando, siempre que las circustancias lo permitían, un trípode.

En algunas ocasiones, la riqueza de la decoración de la capa pictórica sólo se apreciaba a simple vista, no quedando reflejada a través de la documentación fotográfica; es por ello que ésta se ve completada con un registro gráfico a través de la realización de calcos digitales (Íñiguez, 2014). Esto ha permitido, además, efectuar una restitución gráfica de los elementos decorativos faltantes, haciendo más comprensible el esquema decorativo.

La documentación gráfica de calcos digitales se ha realizado a través del programa Adobe Photoshop CS5. Para ello se ha tomado como base una fotografía digital del fragmento a documentar, teniendo precaución de que la toma de la misma fuese completamente ortogonal a la capa pictórica, reduciendo de esta manera las deformaciones provocadas por la perspectiva y la óptica.

Debido al mal estado de conservación y a la escasa policromía que presentan los revestimientos que aquí se estudian, se ha decidido realizar, además del calco que refleja la decoración existente, una reconstrucción virtual. Para que dicho procedimiento no pierda el carácter científico en favor de la espectacularidad, se acompañan de una escala de veracidad realizada con una graduación de tonos en base a la escala de representación de evidencia histórica creada por Aparicio y Figueiredo (2016). 


\subsection{Toma de muestras}

A la hora de tomar las muestras se ha buscado que fuesen representativas de la obra completa a estudiar, que estuviesen lo menos alteradas posibles y que su localización y la cantidad de muestra que se tomaba no afectase a la imagen de la obra.

Se han tomado un total de 22 muestras, procedentes tanto de la capa pictórica como del mortero, que han sido analizadas mediante diversas técnicas que a continuación se detallan.

\subsection{Análisis de muestras}

Para la caracterización de los materiales constitutivos y de la técnica de ejecución de estas pinturas murales, se han analizado las muestras tomadas mediante las siguientes técnicas:

- Microscopía estereoscópica: Se ha realizado una primera aproximación a todas las muestras mediante un microscopio estereoscópico NIKON SMZ1000. Esta técnica presenta dos grandes ventajas: por un lado, permite observar en mayor profundidad el mortero otorgando una imagen ampliada de los distintos estratos, así como las características macroscópicas de la capa pictórica; por otro, favorece la selección de las muestras a analizar mediante técnicas complementarias, reduciendo el número de muestras a estudiar con métodos más complejos.

- Asimismo, esta técnica ha permitido la preparación de las muestras que iban a ser analizadas posteriormente en el microscopio electrónico de barrido (SEM), montadas directamente en portamuestras y sin metalizar. La toma de fotografías de estas muestras facilita sobremanera su estudio en el SEM dado que ofrece una referencia visual a color de lo que en el microscopio electrónico se ve sólo en escala de grises; de esta manera, se puede elegir concretamente el punto a analizar teniendo, además, la referencia del color, aspecto que en este estudio se hace indispensable puesto que dos pigmentos de distinto color pueden tener la misma composición elemental.

- Microscopía óptica polarizada con luz reflejada (MOP): es una técnica básica para la identificación de fases y aspectos texturales, permite tomar imágenes en color muy útiles para el estudio, además de ser complementaria a otras técnicas de análisis. Para ello, ha sido necesario preparar las muestras en forma de láminas delgadas. Para estos estudios se han empleado los microscopios Carl Zeiss-Jena Jenalab y Olympus BX-60, este último con sistema de microfotografía DP-20.

- Microscopía electrónica de barrido (SEM): proporciona estudios composicionales y texturales en las estratigrafías pictóricas. Permite la obtención de imágenes de electrones retrodispersados, así como microanálisis puntuales por dispersión de energía de rayos $\mathrm{X}$, caracterizando la composición elemental de la muestra. Para ello se ha utilizado un microscopio electrónico de barrido S-510 de HITACHI, equipado con un espectrómetro de energía dispersiva de rayos-X (EDX), Rontec, M Series, Edwin, Si (Li) y empleando el software de microanálisis Edwin de Rontec.

- Para el análisis mediante microscopía electrónica de barrido, las muestras han sido preparadas de tres maneras distintas. En primer lugar, algunas de ellas han sido montadas directamente sobre un portamuestras con cinta de carbón; éstas no han sido metalizadas, haciendo posible el posterior análisis por otras técnicas de aquellas que tuviesen un mayor interés. En segundo lugar, las muestras preparadas en láminas delgado-pulidas empleadas en el estudio mediante microscopía óptica han sido cubiertas de una fina capa de carbono para su estudio en el microscopio electrónico. Finalmente, otro número de muestras ha sido preparado en probetas pulidas y han sido, igualmente, metalizadas por una fina capa de carbono.

- Difracción de rayos $X(D R X)$ : esta técnica ha permitido la identificación de las fases minerales cristalinas constituyentes del mortero, además de la cuantificación de su proporción. Los análisis se han realizado mediante el método de difracción de polvo con un difractómetro BRUKER D8 ADVANCE con detector BRUKER LYNXEYE y se han procesado los datos mediante el programa XPowderX. 
- Espectroscopía infrarroja por transformada de Fourier: se ha empleado principalmente en el análisis de las preparaciones y los componentes de recubrimientos o barnices. Los análisis se han llevado a cabo entre 4400 $\mathrm{cm}^{-1}$ y $370 \mathrm{~cm}^{-1}$, en pastillas de $\mathrm{KBr}$ o mediante análisis superficial usando la técnica UATR (Universal Attenuated Total Reflectance).

- Cromatografia en fase gaseosa acoplada a espectrometría de masas: ha sido utilizada para la determinación de sustancias lipófilas como aceites secantes, resinas y ceras; y de sustancias hidrófilas, como las proteínas y las gomas - polisacárido. Para los análisis de sustancias lipófilas, las muestras se tratan con el reactivo de metilación Meth-prep II. Para los hidratos de carbono y las proteínas se lleva a cabo una hidrólisis con $\mathrm{HCl} 6 \mathrm{M}$ asistida por microondas y una derivatización con BSTFA en piridina de los ácidos grasos, aminoácidos y monosacáridos resultantes.

\section{Resultados}

Se han conservado dos paños de pintura mural de considerables dimensiones aunque de forma irregular, de $165 \times 119 \mathrm{~cm}$ y $105 \times 75 \mathrm{~cm}$ aproximadamente cada uno, que, a pesar de su estado de conservación, han permitido conocer el esquema compositivo de los revestimientos, además de otros más pequeños, cuyas dimensiones oscilan entre $30-50 \mathrm{~cm}$ de largo y 10-30 cm de ancho (Fig. 2).

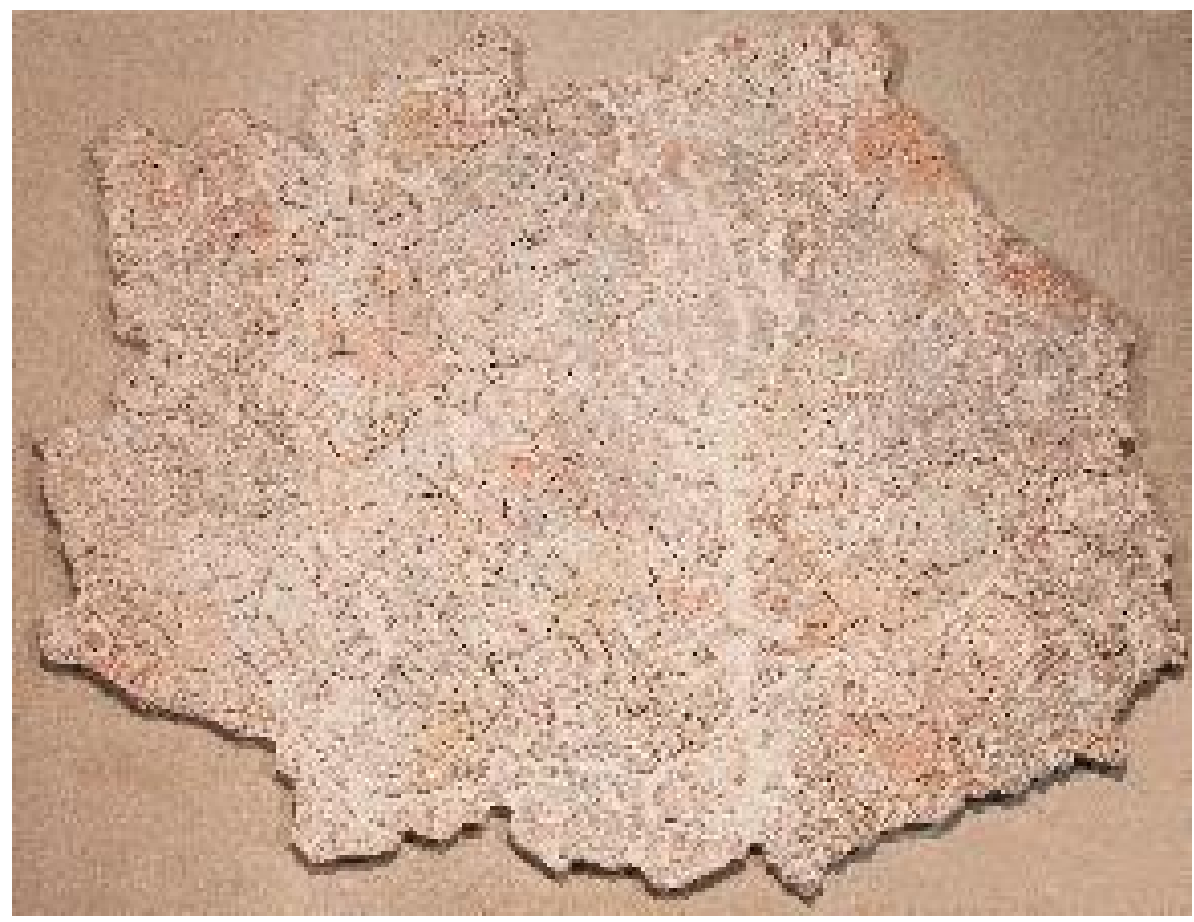

Fig. 2 Uno de los paños de pintura mural conservados

\subsection{Esquema decorativo}

Como se ha señalado en la metodología, para estas pinturas se ha realizado una reconstrucción virtual de la decoración mediante un calco digital, extrapolando la información existente en algunas zonas de los revestimientos en los que se conservaba la policromía en buen estado (Fig. 3). Gracias a ello se puede observar que el esquema compositivo presenta una combinación de decoración geométrica y vegetal. La primera de ellas consiste en una sucesión de franjas diagonales, cuyos colores se alternan dotando de cierta profundidad, y en cuadrados monocolor que se insertan dentro de dichas bandas también de manera alterna. Por otro lado, con una alineación diagonal, se suceden rombos dobles y cuadrados simples realizados a mano alzada en un tono rojo oscuro, dentro de los cuales se representan motivos florales. Finalmente, la composición se completa con flores esquemáticas formadas por cuatro trazos semicirculares que se alternan con los cuadrados monocolor nombrados anteriormente. 


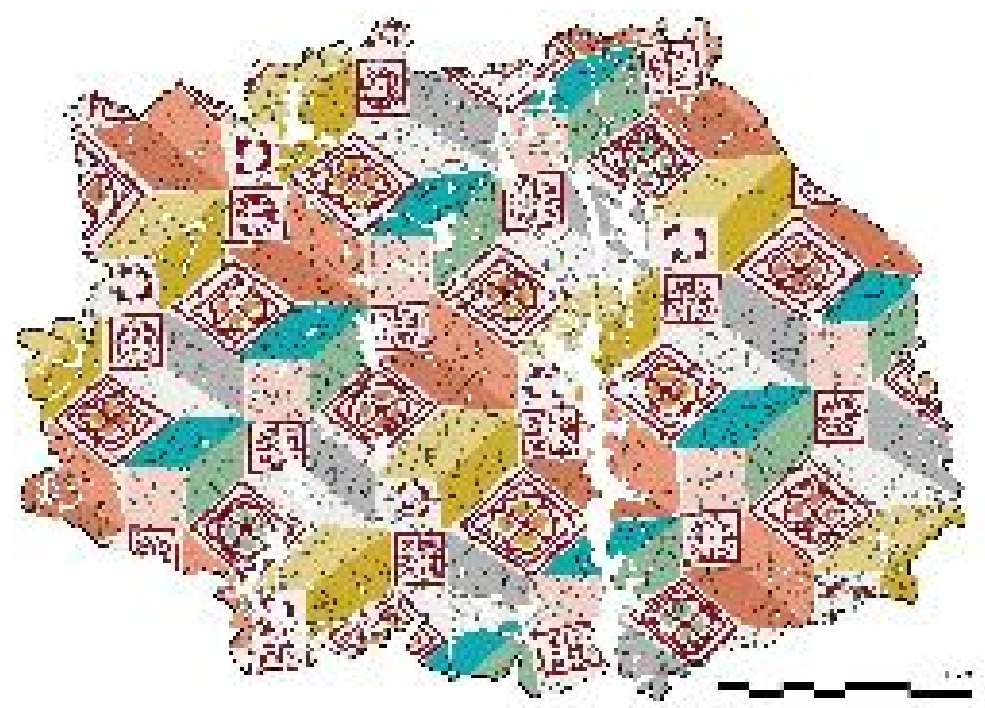

Fig. 3 Reconstrucción virtual de la decoración

A excepción de los pétalos de las flores incluidas en los rombos dobles que, en ocasiones, presentan una superposición de dos tonos, el resto de la composición está formada por colores planos y en un solo estrato.

Como se puede apreciar en el calco que presenta la decoración conservada y en el correspondiente a la escala de veracidad (Figs. 4 y 5), los colores que mejor se han conservado son los rojos y amarillos; por el contrario, en el caso de los azules, sólo es posible apreciar, mediante un estudio de la superficie muy exhaustivo, algunos restos de pigmento, cuya localización coincide con el esquema planteado. La cantidad de pigmento conservado en este caso es tan ínfima y su estado de conservación tan degradado que ha imposibilitado la toma de muestra y su posterior análisis composicional.
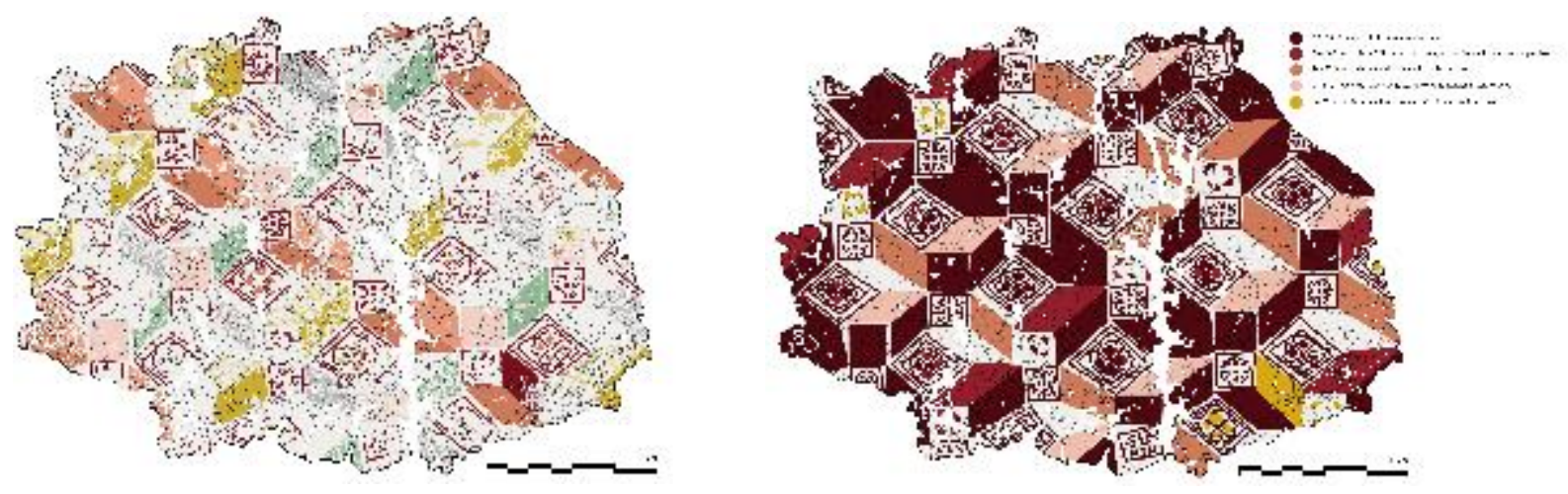

Figs. 4 y 5 Calco con la decoración conservada y escala de veracidad

\subsection{Caracterización de materiales}

El estudio de las distintas muestras ha permitido caracterizar tanto los materiales constitutivos de estos revestimientos como su técnica de ejecución que a continuación se exponen.

\subsubsection{Soporte}

El análisis visual realizado a estas pinturas murales ha permitido identificar un soporte compuesto por un solo estrato de mortero, de un grosor que oscila entre 1 y $1.5 \mathrm{~cm}$. Asimismo, gracias al estado de conservación que presentan ha sido posible identificar el sistema de agarre empleado, correspondiente a la realización de incisiones en forma de espiga en el mortero anterior; éste podría haber sido un mortero de nivelación extendido sobre el muro, aunque no se ha conservado en ninguna zona del revestimiento (Fig. 6). 


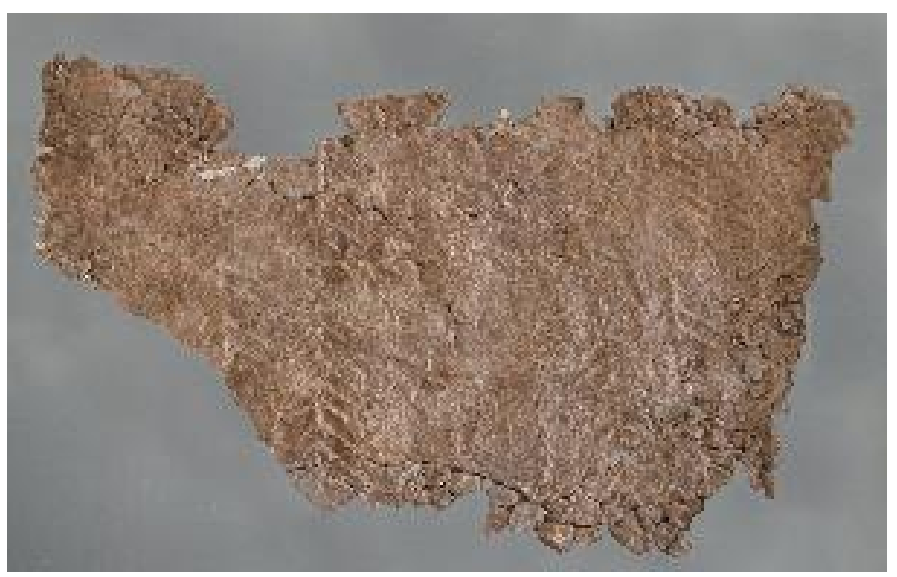

Fig. 6 Reverso de uno de los paños de pintura mural donde se aprecia las incisiones en forma de espiga

Los análisis efectuados mediante difracción de rayos X han caracterizado un mortero compuesto por calcita, cuarzo, feldespato potásico, plagioclasas, dolomita y moscovita. Si bien la cuantificación de las distintas fases cristalinas es aproximativa, la calcita nunca aparece como el elemento mayoritario, aunque gracias a los análisis realizados mediante SEM-EDX ha sido posible corroborar que corresponde a la matriz del mortero.

Por otro lado, el análisis visual realizado mediante microscopio óptico y microscopio estereoscópico ha permitido identificar las características visuales del árido empleado. Gracias al primero de ellos se ha reconocido la irregularidad que el árido presenta en su morfología; en cuanto al microscopio esteresocópico, ha evidenciado cómo, al no haber sido espatulado el mortero, el árido grueso se presenta distribuido de manera homogénea en todo el estrato, provocando una superficie rugosa, llegando incluso a apreciarse el árido de mayor tamaño en la misma capa pictórica (Fig. 7).
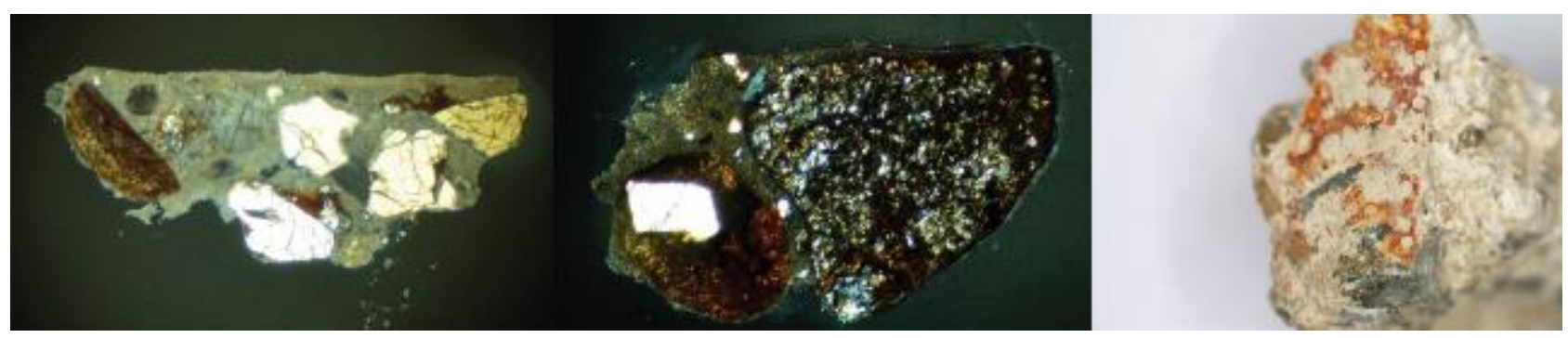

Fig. 7 Muestras analizadas mediante MOP (izquierda y centro) donde se aprecian las características del árido y muestra analizada mediante microscopía esteroscópica (derecha) donde se evidencia cómo el árido grueso, en ocasiones, se aprecia en la capa pictórica

\subsubsection{Pigmentos}

Como ya se ha mencionado, el estado de conservación de los revestimientos ha imposibilitado la toma de muestra de algunos pigmentos, éste ha sido el caso del negro y el ocre, así como de los pocos granos de pigmento azul conservados. El pigmento negro ha podido ser caracterizado por los granos de dicho color identificados en la policromía roja, empleados para oscurecer el tono.

- Rojos y naranjas: se trata del color mayoritario de la composición. Los análisis efectuados por SEM-EDX han identificado óxido de hierro en todas las muestras analizadas de estos colores, señalando que se ha empleado hematites como pigmento.

- Las distintas tonalidades de rojo presentes en la decoración han sido obtenidas al mezclar, en ocasiones, la hematites con negro de humo o carbón y, en otras, con negro de hueso, habiéndose identificado C y P respectivamente como elementos característicos de los mismos. A su vez, en las muestras de color naranja se ha identificado una mezcla de tierras ricas en hematites; en estos casos no se ha empleado pigmento negro para oscurecer el tono. 
- Verdes: el estado de las muestras que se pudieron tomar de esta tonalidad sólo ha permitido su análisis mediante microscopio estereoscópico y mediante SEM-EDX con la muestra sin preparar. Dichos análisis han identificado como elementos característicos $\mathrm{Fe}, \mathrm{K}, \mathrm{Al} \mathrm{y} \mathrm{Mg}$, correspondientes al uso de glauconita y celadonita, minerales que componen las tierras verdes. No se puede descartar, por el momento, el uso de otros pimgentos de este color, del tipo del azul egipcio o la azurita, ya que en una de las muestras estudiadas se han identificado trazas de $\mathrm{Cu}$.

- Blancos: en la composición decorativa de estos revestimientos el blanco parece actuar más como un fondo que como un elemento decorativo en sí. Según el análisis realizado a las distintas muestras, el estrato de pintura blanco, aunque presenta pérdidas, aparece extendido por toda la superficie; ello podría deberse a la aplicación de una fina lechada de cal que mejorase la carbonatación; debido a la irregularidad de la superficie, ésta se habría fijado y conservado mejor en unas zonas que en otras, haciendo que en ocasiones la policromía sí se aplique sobre ella mientras que en otras zonas se aplicaría directamente sobre el mortero. Es por ello que en el análisis de las distintas muestras aparezca en ocasiones un estrato sutil blanco bajo la policromía, mientras que en otras se aprecia como la capa pictórica se superpone directamente a un grano de árido. Los análisis efectuados mediante SEM-EDX han identificado $\mathrm{Ca}$, Al y Si como elementos mayoritarios, de lo que se deduce que para el blanco se ha empleado carbonato cálcico, blanco de cal.

\subsubsection{Técnica de ejecución}

En cuanto a la técnica de ejecución de estas pinturas murales, los análisis efectuados para la identificación de sustancias orgánicas no han detectado ningún aglutinante, aunque sí abundantes componentes de sistemas microbiológicos (hongos, algas, bacterias) tales como metabolitos, ácidos grasos, glicerol y azúcares.

La identificación inequívoca del material que fija los pigmentos restula de gran dificultad debido, por un lado, a la degradación que suelen presentar los materiales orgánicos y a que la confirmación del uso de carbonato cálcico, atribuida al uso de cal, no es fácil por presentar la misma composición que el soporte, lo que dificulta su diferenciación. Sin embargo, teniendo todo ello en cuenta y constatando el aspecto que presentan algunas de las muestras analizadas, así como su análisis mediante SEM-EDX, se ha considerado probable la ejecución de estos revestimientos siguiendo la técnica al fresco y el empleo puntual de agua de cal para reforzar la fijación del pigmento y elaborar los motivos decorativos de los rombos dobles y los cuadrados simples, así como los contornos de los elementos florales.

\section{Conclusiones}

Tras el análisis de los revestimientos murales que aquí se presentan la primera deducción que se puede hacer es que presentan los mismos materiales que los empleados normalmente en revestimientos de época romana, aunque aplicados de una manera más simplificada, ya que tanto la paleta utilizada como el número de estratos de mortero se ve considerablemente reducido.

Como se ha mencionado, las pinturas presentan un solo estrato de motero cuyo espesor oscila entre $1 \mathrm{o} 1.5 \mathrm{~cm}$; unas incisiones en un posible mortero de nivelación de base en forma de espiga habría favorecido la adhesión del revestimiento al muro. Se ha estimado que en sustitución del enlucido o intonachino se habría extendido una fina capa de cal que serviría también como fondo de la composición. Dicha capa presenta un espesor irregular lo que, unido a la rugosidad del mortero, habría contribuido a que la capa se fijara mejor en unas zonas que en otras (siendo ésta la razón de que se aprecie sólo en algunas de las muestras).

Sobre la capa de cal se extenderían los pigmentos empleando la técnica al fresco para su fijación. En el caso de los dibujos lineales de cuadrados simples y rombos dobles, además de para el contorno de los motivos florales, la fijación del pigmento se reforzaría con agua de cal. Todo ello se realizaría sin la ayuda de un dibujo preparatorio y empleando, para ello, una paleta muy semejante a la romana, aunque más reducida. 
Finalmente, cabe destacar que la superficie no ha sido espatulada; esto hace que el árido esté distribuido de manera más homogénea y que el más grueso quede distribuido de forma regular, apreciándose en ocasiones en la capa pictórica. Por otro lado, no se han encontrado, por el momento, paralelos del esquema compositivo que presentan estas pinturas.

\section{Agradecimientos}

Queremos constar nuestro más profundo agradecimiento al equipo del proyecto FORVM MMX, en especial a su director, Marcelo Castro, y a Bautista Ceprián y a $\mathrm{M}^{\mathrm{a}}$ Paz López, por permitirnos y facilitarnos el estudio de estas pinturas murales. Este trabajo ha sido financiado por el Ministerio de Economía y Competitividad y por el Fondo Europeo de Desarrollo Regional (MINECO/FEDER, EU) en el marco del Proyecto de Investigación de referencia HAR2015-66139-P, "Estudio científico y tratamientos de conservación en revestimientos arquitectónicos de época romana a medieval".

\section{Referencias}

Aparicio, P., y Figueiredo, C. (2016). El grado de evidencia histórica-arqueolóica de las reconstrucciones virtuales: hacia una escala de representación gráfica. Otarq, 1, 235-247.

Barbet, A. (1987). Qu'attendre des analyses des pigments?. En Delamare, T.H.F., Datation-caractérisation des peintures pariétales et murales (pp. 155-169). Ravello: European University Centre for Cultural Heritage.

Blázquez, J. M. (2015). La Traditio Legis de Cristo a Pedro y Pablo en un plato de vidrio de Cástulo, Linares (Jaén). Espacio, tiempo y forma. Serie II. Historia Antigua, 28, 137-146.

Blázquez, J. M., y García-Gelabert, M. P. (1988). Cástulo, Jaén, España: I. Excavaciones en la necrópolis ibérica del Estacar de Robainas (s. IV a.C.). BAR International Series 425.

Blázquez, J. M., y García-Gelabert, M. P. (1994). Notas acerca del urbanismo romano de Cástulo (Jaén, España). Ktema, 19, 155168.

Calabria, I. M. (2013). Las pinturas murales de la ciudad íbero-romana de Cástulo. Linares (Jaén). Estudio técnico y propuesta de diferentes sistemas de anclaje para su musealización. Trabajo Fin de Máster. Valencia: Universidad Politécnica de Valencia.

Calabria, I., y Zalbidea, M. A. (2019). Estudio de las pinturas murales de la sala del Mosaico de los Amores de la ciudad íberoromana de Cástulo. Ge-conservación, 16, 45-61.

Castro, M. (1994). El plan especial de Cástulo. Tentativas, líneas directrices y metodología. Cuadernos de Patrimonio. Conservación Arqueológica. Reflexiones y debate sobre teoría y práctica, 3, 76-104.

Ceprián, B., Expósito, D., Soto, M., y López, M. P. (2014). Hallazgos monetarios para el conocimiento de la secuencia estratigráfica en Cástulo. En P. Grañeda (Presidencia), XV Congreso Nacional de Numismática, Madrid.

Contreras, R. (1967). La cuestión del nombre. Oretania, 25-26-27, 9.

Expósito, D., Castro, M., Arias, F., Pedrosa, J. M., y Ceprián, B. (2015). A large glass dish from Cástulo (Linares-Jaén, Spain) with an engraved representation of Chris in Majesty. En S. Fünfschilling (Presidencia), Annales du 20 Congrès de l'Association Internationale pour l'Historie du Verre, Fribourg.

García-Gelabert, M. P. (1987). Evolución socio-política de Cástulo: sociedad de jefatura. LVCENTVM, 6, 29-41.

Íñiguez, L. (2014). Novedades en la metodología para el estudio de la pintura mural romana. En M. Martín-Bueno y J. C. Sáenz Preciado, Modelos edilicios y prototipos en la monumentalización de las ciudades de Hispania (pp. 163-167). Zaragoza: Monografías arqueológicas. 